\title{
THE TECHNOLOGICAL EVALUATION OF SOURDOUGHS PREPARED IN DIFFERENT CONDITIONS
}

\author{
Claudia Felicia, OGNEAN \\ Lucian Blaga University of Sibiu, Romania, claudia.ognean@ulbsibiu.ro
}

\begin{abstract}
The use of sourdough in bread production lead to development of safe, healthy and more palatable product and also contribute to the sustainability of breadmaking through low demands for additives and preservatives. Sourdoughs type I were obtained with different flour: water ratio: 1:0.6;1:1;1:2 and 1:3 and different refreshment ratio 1:3 and 1:4. The sourdough were evaluated for theirs $\mathrm{pH}$, Total Titratable Acidity (TTA), lactic and acetic contents, gas production power. The use of low water level induce a higher TTA and $\mathrm{pH}$ but the yield of acid production was more favourable for the sourdough with higher water content. The higher water content was favourable to formation of lactic acid and induced a better lactic: acetic acid ratio, 15.5 which was by far superior to the 6.5 ratio obtained in the driest dough. The more liquid sourdough had a better ability to produce gases. Flour : water ratio 1:2 are recommended to obtain high quality sourdough, with a better smell and taste, with a high yield, easy to handle and using relative low spaces. Refreshment ratio 1:4 delivery comparable results with 1:3 refreshment ratio and implies lower volumes for fermentations.
\end{abstract}

KEY WORDS: bread, sourdough, wheat flour, sustainability

\section{INTRODUCTION}

Bakery products are perceived by the most of consumers as bland, unhealthy and not nutritive [1]. Improvement of taste, smell and nutritive values of breads could transform this important part of human diet in to an important vector for population's health. Sourdough proved to be an effective method to transforms bread in to a more attractive product which contributes to a sustainable development of society. Breads prepared with sourdough reduced the postprandial glycaemia and the level of insulin in blood [2,3]. Rizzelo et al. [4] founded that the Glycaemic Index of whole bread leavened with yeast was $72.0 \%$ while the use of sourdough reduce the Glycaemic Index to $53.7 \%$.

Modern diet is characterised by a low fibres intake, which on long term induce different affection as constipation, obesity, colon tumours, diabetes type 2 [5]. Some Lactic Acid Bacteria (LAB) have the potential to produce in dough exopolysaccharides with prebiotic [6], antitumor and immunomodulation effects [7].

The consumers pot pressure on food producers to increase food diversity. New pseudocereals as quinoa and amaranth as the forgotten ones as sorghum, buckwheat, spelt, millet are introduced in bread but their acceptability is low due the different taste, aroma and texture.

Sourdoughs could be used to produce high nutritional breads which include in theirs recipes other cereals as rye, oat and barley $[8,9]$. Efforts are taken to improve the quality of these products [10]. The use of sourdough improved the acceptability of quinoa bread and delay with 4 day mould development [11].
The use of preservatives and additives used to prevent mould development, rope disease and bread stalling could be reduced through the use of sourdough [12]. Some species of Penicilium, Sacharomyces and Zygosaccharomyces developed tolerance to potassium sorbate [13]. We are pressed to develop new safe foods. As Steinkraus [14] postulated fermented foods are generally safe. Antistaling effect of sourdough's use in bakery was proved through a smaller increasing of crumb firmness $[15,16]$. The bread firmness is improved through increasing of specific volume and reduces starch retrogradation.

\section{MATERIAL AND METHODS}

For the sourdough preparation was used commercial whole wheat flour available on market and tap water to reproduce home conditions. Flour and water were mixed in flour: water ratio $1: 0.6 ; 1: 1 ; 1: 2$ and $1: 3$. The inoculum of lactic acid bacteria and wild yeast consisted in sourdough prepared in previous day. The proportion was 3 parts fresh dough and 1 part fermented dough. For the sourdoughs prepared from 2 part of flour and 1 part of water was prepared also a sourdough with 1 part fermented dough for 4 parts fresh dough. The fermentation was conducted at $25^{\circ} \mathrm{C}$, for 3 weeks, refreshed daily.

The $\mathrm{pH}$ was measured immediate after preparation and after $24 \mathrm{~h}$ of fermentation with an electrode HANNA INSTRUMENTS FC200B, designed for semisolid food by direct immersion in dough. The total titratable acidity (TTA) was determined by titration with $\mathrm{NaOH}, 0.1 \mathrm{~N}$ until $\mathrm{pH} 8.5$ and after 10 min resting the titration was continued until final $\mathrm{pH}$ 8.5 stable for 1 min was reached. The $\mathrm{pH}$ was measured with $\mathrm{pH}$ electrode. 
The lactic and acetic acids from sourdough were determined by HPLC, SmartLine Knauer 5000 equipped with autosampler Knauer 3950, degassing system Smartline Knauer 5000, pump Smartline Knauer 1000 and UV-VIS detector Smartline Knauer 2550. Mobile phase used was monosodium phosphate $100 \mathrm{mM}$ with $\mathrm{pH}$ adjusted to 2.5 with phosphoric acid. We used chromatographic column Macherey-Nagel EC Nucleodur 100$5 \mathrm{C} 18 \mathrm{ec}, 250 \mathrm{~mm}$ length and $4 \mathrm{~mm}$ in diameter. The mobile phase flow with $1 \mathrm{~mL} / \mathrm{min}$ and the injection of sample was $5 \mu \mathrm{L}$, as described by manufacturer of column. The temperature oven was $25^{\circ} \mathrm{C}$. Detection was made spectrophotometric, at $210 \mathrm{~nm}$. The acetic acid, lactic acid for calibration and other chemicals was purchased from Sigma Aldrich, HPLC grade.

The gas production of sourdough was measured. The same whole wheat flour used in sourdough preparation was mixed with sourdough for each $100 \mathrm{~g}$ flour d.b. $25 \mathrm{~g}$ sourdough d.b and water was added to obtain desired dough's moisture, $53.75 \% .150 \mathrm{~g}$ of dough was introduced in a flask and after $1 \mathrm{~h}$ of incubation was measured the time necessary to produce 50 and $100 \mathrm{ml}$ of gas.

The API $20 \mathrm{C}$ AUX, (Biomeriux, France) tests were ruled for each final sourdough obtained. These tests identify the yeast genus through the differences between yeast to metabolise different carbohydrates.

The experiments was realised in duplicate and triplicates

\section{RESULTS AND DISCUSSION}

The sourdough designed to be used in bakery must be stable. The stability of the dough is assured by low $\mathrm{pH}$ which inhibits the LAB activity so the physical and chemical characteristics will be constant over a period of time. The $\mathrm{pH}$ of sourdough should be under 4 , close to 3.8. At this $\mathrm{pH}$ the lactic acid and acetic acid will be finding in undissociated form and will go through cellular membrane and inhibit the cellular metabolite. The $\mathrm{pH}$ of obtained sourdough varied between 3.59 and 3.78. The higher $\mathrm{pH}$ was observed at the sourdough with a low flour: water ratio, $1: 0.6$. The $\mathrm{pH}$ was lower as the moisture of sourdough increases. The $\mathrm{pH}$ of sourdoughs prepared with different refreshment ratio were practical the same, 3.66. The closer values of $\mathrm{pH}$ show that after $24 \mathrm{~h}$ of inoculation the fermentations was stopped due the inhibiting effects of low $\mathrm{pH}$. For these conditions of fermentation it is possible to reduce time of incubation but experiments must be conducted to study the evolution of $\mathrm{pH}$ during fermentation.

The $\mathrm{pH}$ of sourdough is influenced by the quantity of acids present in flour and formed during the fermentations, the acids species presents and the buffering capacity of flour used. A higher proportion of wheat flour in sourdough will ensure a higher amount of buffering substances. This effect of buffering was observed when TTA of sourdoughs was determined. The results are presented in Figure 1. The acidity of sourdough with flour:water ratio 1:6 was almost twice as the TTA of dough with lowest proportion of flour, 22.2 and respective $10.6 \mathrm{~mL}$ $\mathrm{NaOH} 1 \mathrm{~N} / 100 \mathrm{~g}$ sourdough. The acidity varied much more with the water content of sourdough than $\mathrm{pH}$, which indicates that the microorganisms' activity was dependent to level of $\mathrm{pH}$.

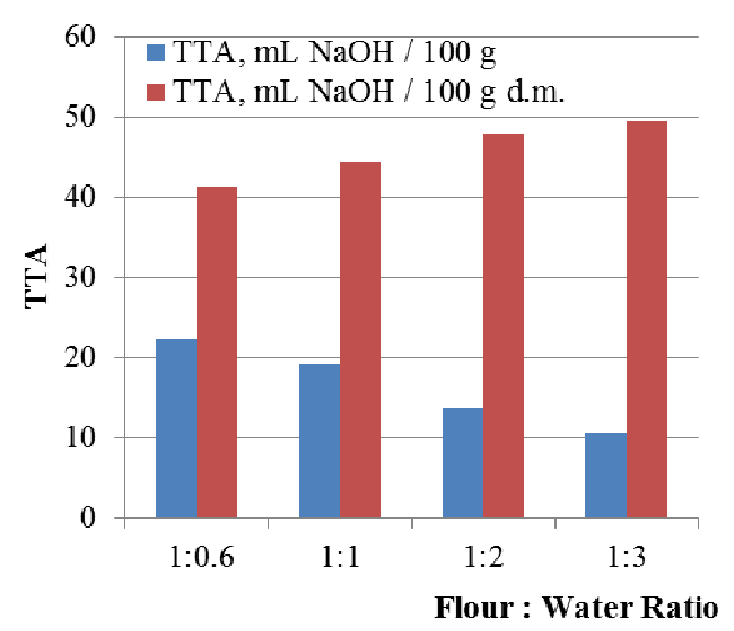

Figure 1. The TTA and of sourdough prepared with different flour: water ratio

We consider the yield of acid as the TTA related to the dry matter of sourdough. The values are presented in Figure 2. These values were more favourable to the doughs with higher moisture content, where the quantity of acids formed was higher. The values are quite higher if we consider the initial acidity of flour used to prepare the sourdough. The higher water content was favourable to acid formation through fermentation probably due the higher degree of starch saccharification. When the initial quantity of sourdough used as inoculum was lower (1:4 instead 1:3) very small increasing of TTA was observed, from 47.9 to $50.1 \mathrm{~mL} \mathrm{NaOH} \mathrm{1N/100} \mathrm{g}$ dry basis sourdough.

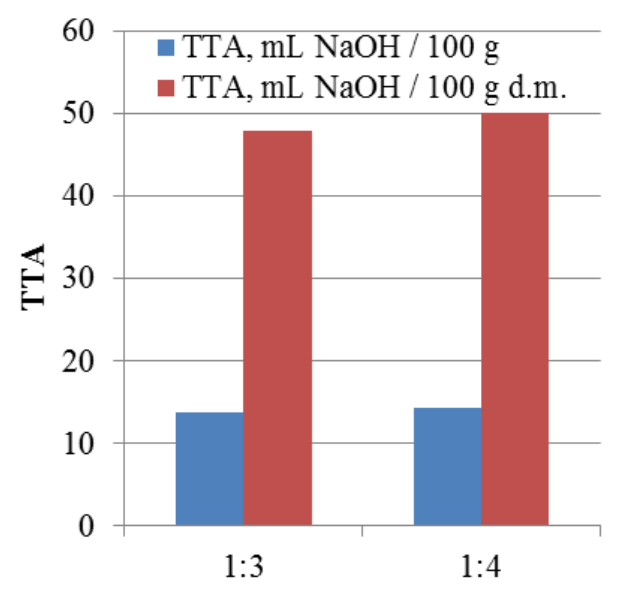

Refresment Ratio

Figure 2. The TTA of sourdough prepared with flour: water ratio $1: 2$ and different refreshment ratio

The main products of lactic fermentation are lactic acid and acetic acid. They are produced through LAB's fermentation of sugars available in dough and yeast could contribute too at the production of acetic acids. The lactic and acetic acids present in sourdough after 21 refreshments at $25^{\circ} \mathrm{C}$ were determined through HPLC. The amounts of acids species (Figure 3) varied similar as the TTA of sourdough but not the same. 


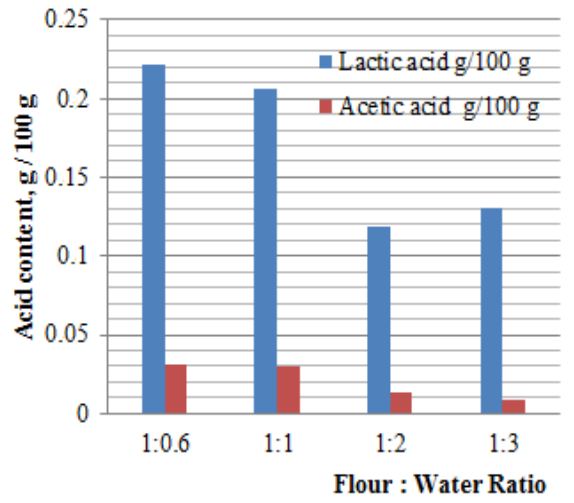

Figure 3. The lactic and acetic concentration in sourdough with different flour: water ratio

The differences could be observed more easily from the Figure 4 where the ratio between the two species is presented.

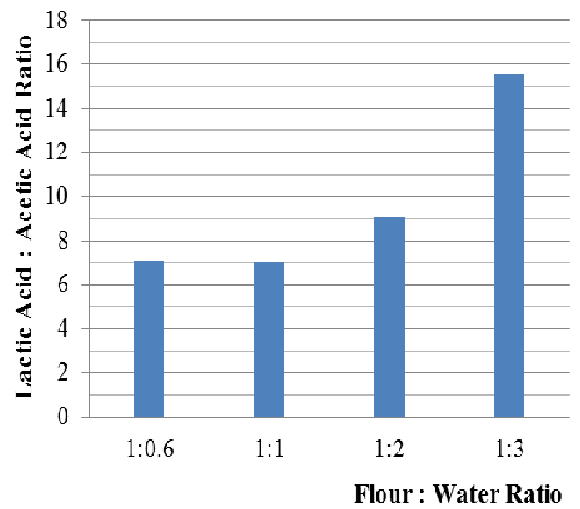

Figure 4. The lactic acid: acetic acid ratio in sourdough with different flour: water ratio

From the figures could be observed that the moisture of dough have $o$ very powerful influence on the selection and propagation of microorganisms present in sourdough, the more fluid the dough the higher ratio of lactic acid formed. The balance of lactic and acetic acids is very important as the acetic acid have a more powerful taste and smell. The lactic acids are more desirable in baking than acetic acids and LAB with a higher yield of lactic acid are preferred. In the wettest doughs the ratio between lactic and acetic acid was more than doubled than in the case of driest dough. Even in the driest dough the ratio had a good values, higher than 80: 20, minimal value indicated by Belitz and Grosch [17] for a desirable bread. Some authors indicated that the LAB prefer a more consistent doughs while yeast a more fluids medium. The most fluids sourdough should have a higher concentration of acetic acid. The moisture from sourdough probably influenced the selection of LAB and favoured the species which produced high amount of lactic acid and low amount of acetic acid. The results are in accordance with the sensorial evaluation of sourdoughs were the doughs with a higher water content had a milder and more pleasant taste and smell than the sourdough with low water content.

The refreshment ratio had not influenced very much the final TTA but influenced the concentration of lactic and acetic acid. The quantity of lactic acid increased with $20 \%$ when the inoculum was smaller and the ratio of lactic acid and acetic acid also increased from 9.1 to 10.1 .

In the process of sourdough formation not only LAB flourish, also wild yeast present in flour developed and theirs number increases. The yeast are responsible for acidification through acetic acid formation and, more important for gas formation. Not only yeast formed gas during fermentation, heterofermentative LAB also produced small amounts of gases. In the traditional baking the development of bread volume was due the activity of LAB and wild yeast present in sourdough. The modern baking replaced the sourdough with a low production of gas with selected species of yeasts, mainly Sacharomyces cerevisiae, which have a high power of gas production. To evaluate the sourdoughs' gas production power we prepared doughs with the same amount of sourdough as d.m. and we measure the time necessary to produce 50 and 100 $\mathrm{ml}$ of gas. The results are presented in the Figure 5.

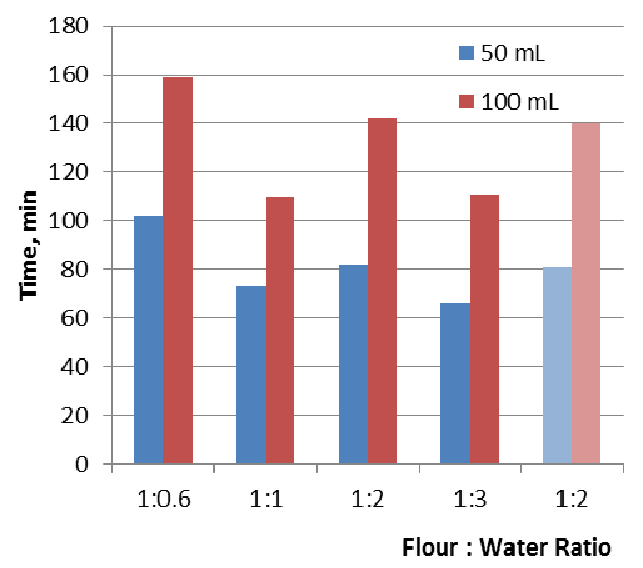

Figure 5. Power of gas production of sourdoughs with different flour: water ratio and refreshment ratio.

In accordance with the data from literature the driest sourdough showed the lower capacity to form gases, the yeast developed slower. In the more wet doughs the yeast was more active and the time needed to produce $50 \mathrm{ml}$ and $100 \mathrm{~mL}$ of gases was lower. No relations could be observed between the water content and the power of gas production, dough with flour: water ratio 1:2 had a lower power of gas production than the dough with ratio 1:3. This observation proved that the sourdoughs are very complex ecosystems and different species of organisms could flourish according with the conditions of cultivation, although the same materials were used for doughs preparations. The observation made on microscope on fixed and methylene blue dyed confirm that. In figure 6 are presented images of sourdough.

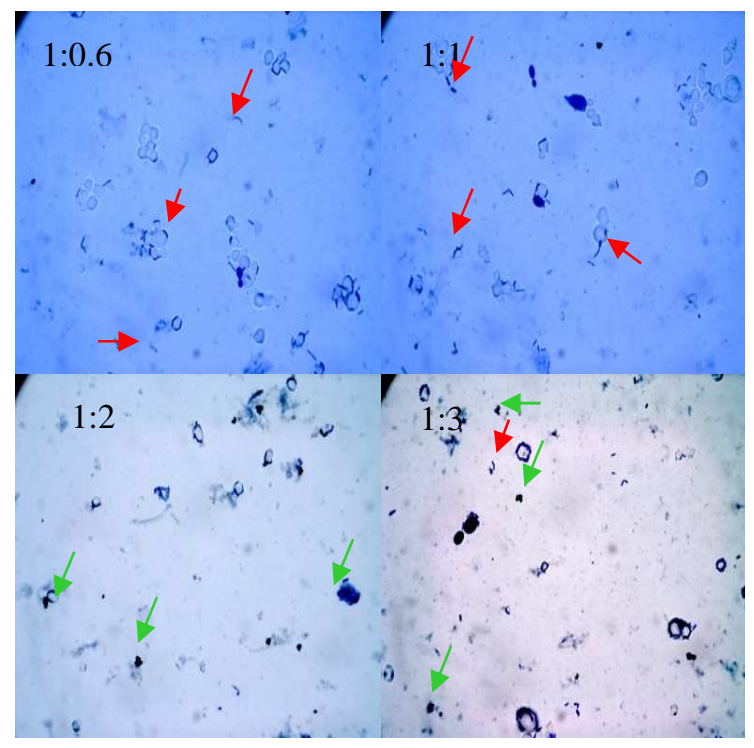

Figure 6. Microscopic view of methylene blue dyed sourdough with different flour:water ratio and refreshment ratio (100x magnification) 
In pictures obtained through microscopic view of sourdough we observed a large number of bacteria and some yeasts cell. In the first two images of driest sourdough could be observed a large number of rod shape pairs of bacteria (red arrow) while in the others doughs, more fluid appeared a large number of spherical cell, alone or grouped in two, four or cluster of cell (green arrow). The yeast cell differed in shapes and dimensions but almost all of them presented buds which indicate that they were active in the doughs.

API testes were ruled to identify the yeasts present in sourdoughs. Saccharomyces cerevisiae was founded present only in the dough with flour:water ratio 1:3. Other species common found in sourdough could not be identified by this test. This test identify species with a metabolism equivalent to Cryptococcus terreus in sourdoughs with four:water ratio 1:0.6, $1: 1$ and 1:2, while in sourdough with flour:water ratio 1:2 and refreshment ratio 1:4 was identified Candida zeylandia (70\%), Cryptococcus terreus (20\%) and Candida albicans $(7 \%)$.

\section{CONCLUSIONS}

- The sourdough production is relative simple and did not need complicated installations but products with different characteristics could be obtained from the same raw materials just by varying the ratio between them. Sourdoughs are complex ecosystems. For a bakery plant which show interests in the use of sourdough working condition and recipe should be carefully choose. If a high acidification of dough and bread is desired the sourdough with low water content should be used but the sourdough is very consistent and sticky and difficult to manipulate. The sourdough with flour:water ratio 1: 1 was very similar to the dough with 1:0.6 ratio but was less consistent and flow. When the water content was increased the acidification power was reduced but a higher exploitation of raw materials was achieved by higher yield of acids. The sourdough were richer in lactic acid had a more pleasant taste and smell, characteristics appreciated by modern consumers which usually consume modern bland breads with low fermentation. The uses of fluids sourdough could shorten the proofing time through higher quantity of gas formed during fermentation.

- The production of traditional like sourdough (type I) is easy and did not need many resources and have a high potential to develop better breads. By changing the recipe different results could be obtained and promote diversity. Sustainable products will be obtained through the use of sourdoughs.

\section{ACKNOWLEDGEMENTS}

This paper is supported by the Sectoral Operational Programme Human Resources Development (SOP HRD), financed from the European Social Fund and by the Romanian Government under the contract number POSDRU/159/1.5/S/133675.

\section{REFERENCES}

1. Gellynck, X., Kuhne, B., Van Bockstaele F., Van de Walle D., Dewettinck, K., Consumer perception of bread quality, Appetite, 53, pp. 16-23, (2009).

2. Clarke, C.I, Arendt. E.K., A Review of the Application of Sourdough Technology to Wheat Bread, Advances in Food and Nutrition Research, 49, pp. 137-161, (2005).
3. Poutanen, K., Flander, L., Katina, K., Sourdough and cereal fermentation in nutritional perspective, Food Microbiol., 26, pp. 693-699, (2009).

4. De Angelis, M, Rizzello, C.G., Alfonsi, G., Arnault, P., Cappelle, S., Di Cagno, R:, Gobbetti, M., Use of sourdough lactobacilli and oat fibre to decrease de glycemic index of white wheat bread, British Journal of Nutrition, 98, pp. 1196-1205, (2007).

5. Katina, K., Arendt, E., Liukkonen, K.H., Autio, K., Flander, L., Poutanen, K., Potential of sourdough for healthier cereal products, Trends in Food Science \& Technology, 16, pp. 104-112, (2005)

6. Gobbetti, M., Rizzello, C.G., Di Cagno, R., De Angelis, M., How the sourdough may affect the functional features of leavened baked goods, Food Microbilogy, 37, pp. 3040, (2014).

7. Sadeghi, A., The secret of Sourdough; A Review of Miraculous Potential of Sourdough in Bread Shelf Life, Biotechnology, 7, 413-417, (2008).

8. Mariotti, M., Garofalo, C., Aquilanti, L., Osimani, A., Fongaro, L., Tavoletti, S., Hager, A.-S., Clementi, Fr., Barley flour exploitation in sourdough bread-making: A technological, nutritional and sensory evaluation, LWT Food Science and Technology, 59, pp. 973-980, (2014).

9. Flander, L., Suortti, T., Katina, K., Poutanen, K., Effects of wheat sourdough process on the quality of mixed oatwheat bread, LWT - Food Science and Technology, 44, pp. 656-664, (2011).

10. Moroni, A.V., Arendt, E.K., Dal Bello, F., Biodiversity of lactic acid bacteria and yeasts in spontaneously-fermented buckwheat and teff sourdoughs, Food Microbiology, 28, pp. 497-502, (2011).

11. Axel, C., Röcker, B., Brosnan, B., Zannini, E., Furey, A., Coffey, A., Arendt, E.K., Application of Lactobacillus amylovorus DSM19280 in gluten-free sourdough bread to improve the microbial shelf life, Food Microbiology, 47, pp. 36-44, (2015).

12. Leroy, F., De Vuyst. L., Lactic acid bacteria as functional starter cultures for the food fermentation industry, Trends in Food Science \& Technology, 15, pp. 67-78, (2004).

13. Schnurer, J., Magnusson, J., Antifungal lactic acid bacteria as biopreservatives, Trends in Food Science \& Technology, 16, pp.70-78, (2005).

14. Steinkraus, K.H., Fermentations in World Food Processing, Comprehensive Reviews in Food Science and Food Safety, pp. 23-32, (2002).

15. Clarke, C.I., Schober, T.J., Arendt, E.K., Effect of single strain and traditional mixed strain starter culture on rheologicl properties of wheat dough and bread quality, Cereal Chem., 79, pp. 640-647, (2002).

16. Corsetti, A., Gobbetti, M., De Marco, B., Balestrieri, F., Paoletti, F., Russi, L., Rossi, J., Combined effect of sourdough lactic acid bacteria and additives on bread firmness and staling, J. Agric. Food Chem., 48, pp. 30443051, (2000).

17. Belitz, H.-D., Werner, G., Schieberle, P., Food Chemistry, $4^{\text {th }}$ edition, Springer, (2009). 